\title{
EDITORIAL
}

\section{DOSSIÊ COMUNICAÇÃO CIENTÍFICA}

\begin{abstract}
Dalgiza Andrade Oliveira
Doutora em Ciência da Informação pelo Programa de Pós-Graduação em Ciência da Informação (PPGCI) da Universidade Federal de Minas Gerais (UFMG). Professora Associada da Escola de Ciência da Informação (ECI) / Programa de Pós-Graduação em Gestão da Organização e do Conhecimento (PPG-GOC) da Universidade Federal de Minas Gerais (UFMG) dalgizamg@gmail.com https://orcid.org/0000-0002-0814-6325
\end{abstract}

Nivaldo Calixto Ribeiro

Doutorando em Gestão e Organização do Conhecimento pela Escola de Ciência da Informação da Universidade Federal de Minas Gerais (PPGGOC/UFMG). Bibliotecário da Universidade Federal de Lavras (UFLA) nivaldo@ufla.br / zoopas@gmail.com https://orcid.org/0000-0003-0650-0121

A temática da comunicação científica, privilegiada, nesta edição, constitui-se como um dos insumos necessários ao desenvolvimento científico e tecnológico para qualquer área do conhecimento. Comunicar reflexões e resultados de pesquisa é a válvula propulsora da ciência. Hodierno, entende-se que a pesquisa nunca foi tão evocada como tem sido nestes dias pandêmicos. O tema "Comunicação Científica" tem circulado em diversos segmentos, pois são organizados eventos e publicados documentos no intuito de discuti-lo e ampliar o alcance a seu respeito. São disponibilizados trabalhos, artigos, livros, teses e dissertações sobre suas especificidades nos mais diversos canais e formatos, como anais, periódicos e serviços especializados de base de dados, em todas as áreas do conhecimento. Perfis em plataformas de mídias sociais debruçam-se sobre o assunto, desde a concepção de pesquisa, linguagem, fontes de informação, processos editoriais de periódicos até os novos formatos de avaliação.

Evidenciando a temática, vale destacar que a BIBLOS - Revista do Instituto de Ciências Humanas e da Informação, é um periódico de acesso aberto e que comemora 35 anos de seu lançamento. O seu primeiro volume, ainda impresso, foi publicado em 1985 e, na ocasião, abordava questões como: automação de biblioteca, bibliotecas universitárias e acessibilidade. Desde então, vários artigos, com ideias interdisciplinares, características da Ciência da Informação foram publicados, tornando a revista referência em temas diversos, entre eles a comunicação científica, enfoque principal deste Dossiê. Essas pesquisas traziam os resultados de pesquisas relacionados à análise, à coleta, à classificação, ao tratamento, ao armazenamento, à recuperação, à disseminação da informação e às tecnologias afins, na busca pela transformação de dados em conhecimento. 
Neste cenário efervescente, que envolve a comunicação científica, insere-se esta edição especial da BIBLOS, composta por 13 artigos de relevância para a área. Os estudos elucidam que a ciência está intimamente associada à comunicação científica, de forma teórica-metodológica e prática. Assim, compreende-se que a ciência só alcançará suas aspirações por meio da divulgação, da acessibilidade, da transparência, da ética e a da ampla discussão dos resultados das pesquisas entre os pares e focalizando o retorno para a sociedade. Nesta edição, são tratados temas como: competência crítica da informação, redes sociais, recursos imagéticos, periódicos, fator de impacto, ciência aberta, repositórios de dados e institucional, plugins em revistas científicas, design de interação em bibliotecas digitais e estudos bibliométricos.

Com a pretensão de colaborar com a leitura e a organização dos artigos publicados nesta edição especial: Dossiê - Comunicação Científica, os trabalhos foram listados e disponibilizados em três categorias: 1. Comunicação científica, produção científica e estudos bibliométricos; 2. Periódicos, redes sociais e recursos imagéticos e

\section{Ciência Aberta e recursos tecnológicos.}

$\mathrm{Na}$ primeira categoria,a Comunicação científica, produção científica e estudos bibliométricos é a temática da primeira seção, em que a Comunicação e a divulgação científicasão tratadas, no texto de Fernanda Vasconcelos Amaral e Jordan Paulesky Juliani. Os autores investigam as interações entre a comunicação e a divulgação científica e refletem sobre como a ciência pode ser melhor compreendida e assimilada pelo público leigo. Expõem que a comunicação e a divulgação científica são dois processos complementares, que necessitam de um melhor diálogo para que a informação científica alcance o cidadão. Maria Elizabeth Oliveira da Costa e Dalgiza Andrade Oliveira apresentam uma análise quantitativa da produção científica em Educação a Distância no Brasil, publicada em artigos científicos nos periódicos nacionais da área de Educação. Entre as constatações, as autoras perceberam que os fatos históricos, políticas públicas e os investimentos relativos à Educação a Distância podem ter influenciado na produção científica sobre esse tema, na área da Educação. Já a produção científica, no campo da Cancerologia brasileira, é tratada no trabalho de Kátia de Oliveira Rodrigues e Marlene Oliveira, no qual afirmam que a comunicação científica consiste em um processo cíclico, que envolve diferentes etapas, a exemplo da produção e da publicação dos resultados da pesquisa. As autoras buscaram caracterizar 
a produção científica dos docentes-pesquisadores dos programas de pós-graduação, no campo da Cancerologia brasileira, no período 2005-2015. Ana Cláudia de Araújo Santos e Edvaldo Carvalho Alves propuseram, em seu trabalho, a realização de um levantamento bibliográfico sobre a esquistossomose, referente ao período de 1940 a 1949. O corpus de análise foi de 186 artigos, de periódicos nacionais. Constataram o papel preponderante do Instituto Oswaldo Cruz, no desenvolvimento de pesquisas e expedições científicas voltadas para combater essa endemia e no desenvolvimento de uma ciência experimental. A evolução da produção científica sobre o tema "preservação documental em bibliotecas", no período de 1991 a 2018, foi avaliada por meio de um estudo bibliométrico, no trabalho de Lizandra Veleda Arabidian, Cristina Vargas Cademartori e Anelise Beneduzi. Os resultados foram obtidos por meio de uma busca sistemática, realizada no Portal de Periódicos da CAPES, seguindo o protocolo Prisma. O estudo demonstrou um aumento da produção científica sobre a temática de preservação de acervos, nos últimos anos e isso, provavelmente, segundo os autores, tem contribuído para informar e conscientizar sobre a importância da preservação documental. O artigo de Edna da Silva Angelo, Carlos Alexandre de Oliveira, Marlene Oliveira e Thiago Magela Rodrigues Dias buscou identificar o perfil científico dos bolsistas de iniciação científica PIBIC, do CNPq entre os anos de 2001 a 2013, na área de Ciência da Informação do Brasil. O objetivo foi verificar se está contribuindo para a formação de recursos humanos para a pesquisa, por meio de uma perspectiva censitária e de uma análise descritiva. Para os autores, conhecer essa realidade é o tipo de constatação que almeja apoiar as políticas públicas de fomento.

O capítulo sobre os Periódicos, redes sociais e recursos imagéticos abarca, entre outros trabalhos, o estudo de Célia da Consolação Dias, Rafael Gonçalves Dias e Jorge Santa Anna, em que os autores se dedicaram a revelar dados sobre o uso das redes sociais e as imagens na divulgação científica, por periódicos científicos da Ciência da Informação. Os autores detectaram que o uso de redes sociais, como estratégia de divulgação científica tem sido comum, embora tenham identificado que os periódicos poderiam utilizar mais recursos midiáticos e imagéticos para aumentar a visibilidade das pesquisas divulgadas. Cátia Cândida Almeida e Maria Cláudia Cabrini Gracio apresentam aspectos metodológicos e de utilização do Fator de Impacto. Observaram críticas relacionadas à composição dos periódicos na base de dados Web of Science, apontando 
questões de padronização em termos de classificação dos tipos de documentos e à representatividade das áreas científicas e à abrangência regional. $\mathrm{O}$ trabalho de Josiane Ribeiro Prestes, Angélica C. D. Miranda e Simone Firme Machado apresenta um estudo envolvendo 21 revistas científicas da área de Biblioteconomia e Ciência da Informação, com base nos critérios SciELO e a identificação dos plugins Open Journal Systems (OJS) habilitados. Enfatiza que o OJS é um software utilizado para editoração de revistas científicas para divulgação em meio digital bem como que os plugins podem agregar valor às revistas científicas que os utilizam, estabelecendo um melhor relacionamento com os seus leitores.

No que se refere à Ciência Aberta e recursos tecnológicos, Milton Shintaku, Ronnie Fagundes de Brito, Rui Seabra Ferreira Júnior e Benedito Barravieira abordam, em seu estudo, a avaliação aberta pelos pares, um dos movimentos associados à Ciência Aberta que se apresenta como um grande desafio para os envolvidos na editoração científica. Levantam e analisam a literatura disponível sobre esse tema, a fim de identificar conceitos e tendências que possam subsidiar os editores na discussão sobre essa nova modalidade proposta. Identificam que a avaliação duplo-cega reina absoluta, questionam acerca do contato entre avaliado e avaliador, e reforçam a abertura das ciências apesar do enfrentamento às resistências dos produtores do conhecimento científico. Lucas Nóbrega Paganine e Bianca Amaro,em seu artigo sobre estado dos repositórios de dados científicos no Brasil, destacam que o surgimento das novas tecnologias da informação e comunicação (TICs) mudaram as formas como as pessoas interagem e se comunicam, desencadeando mudanças significativas na comunicação científica. Identificam que a realidade brasileira ainda não está preparada, adequadamente, para lidar com as questões ligadas aos repositórios de dados. Davilene Souza Santos e Flávia Goulart Mota Garcia Rosa apresentam o resultado de pesquisa realizada com os programas de Pós-Graduação da Área I da Universidade Federal da Bahia e o Repositório Institucional, no que diz respeito à disponibilização de conteúdo. Por último, nesta seção, a partir de uma pesquisa bibliográfica, Karine Coutinho Drumond e Célia da Consolação Dias relacionam os possíveis elos entre a Ciência da Informação e o Design de Interação, por meio de um mapa conceitual, a fim de descrever, qualitativamente, e identificar as relações e interlocuções que se estabelecem entre as duas áreas em projetos de bibliotecas digitais. O estudo possibilitou evidenciar a interlocução em duas dimensões principais: a dimensão 
histórica e a de projeto. Ainda, constatam que outros elos, como os estudos com usuários, a interação humano-computador, a cognição, a usabilidade e o design centrado no usuário também são discutidos na literatura.

A Ciência da Informação é jovem e com muita margem para evoluir. Nesse construto, perguntas de pesquisa instigantes e interessantes a serem investigadas devem ser levantadas, de forma a fortalecê-la como ciência. Reflexões apontadas nesta edição especial, entende-se que, formam um escopo importante e desafiador, trazendo pontos que contribuem para o debate e para o desenvolvimento da área. Assim, convida-se à leitura dos trabalhos publicados nesta edição especial da BIBLOS - Revista do Instituto de Ciências Humanas e da Informação:Dossiê - Comunicação Científica.

A Ciência da Informação é jovem e com muita margem para evoluir. Nesse construto, perguntas de pesquisa instigantes e interessantes a serem investigadas devem ser levantadas, de forma a fortalecê-la como ciência. Reflexões apontadas nesta edição especial, entende-se que, formam um escopo importante e desafiador, trazendo pontos que contribuem para o debate e para o desenvolvimento da área. Assim, convida-se à leitura dos trabalhos publicados nesta edição especial da Revista Biblos: Dossiê Comunicação Científica. 